\title{
Сроки, способы посадки и регуляторы роста как элементы ресурсосберегающей технологии картофеля
}

\section{И.Н. Романова, С.Е. Терентьев, М.И. Перепичай, К.В. Мартынова}

Исследования проводили с целью изучения способов, сроков посадки клубней среднеспелого сорта картофеля Вектор и выявления наименее энергозатратного способа. Исследования показали, что в условиях Нечерноземной зоны сорт картофеля Вектор позволяет получить урожайность 36-38 т/га. Наименее энергозатратным был гребневой способ посадки.

Ключевые слова: картофель, сроки посадки, способы посадки, ресурсосберегающие технологии, урожайность, регуляторы роста.

$\mathrm{B}$ нашей стране картофель играет особую роль в обеспечении перерабатывающей промышленности сырьем, населения - продовольствием, оставаясь ценным продуктом питания [1].

В то же время его производство в целом носит экстенсивный характер, чему существует целый ряд причин. Поэтому главное направление развития современного картофелеводства в Нечерноземье - внедрение прогрессивных технологий, обеспечивающих, с одной стороны, получение высоких сборов продукции с единицы площади, с другой - отвечающих требованиям экономической и энергетической эффективности [2, 3, 4].

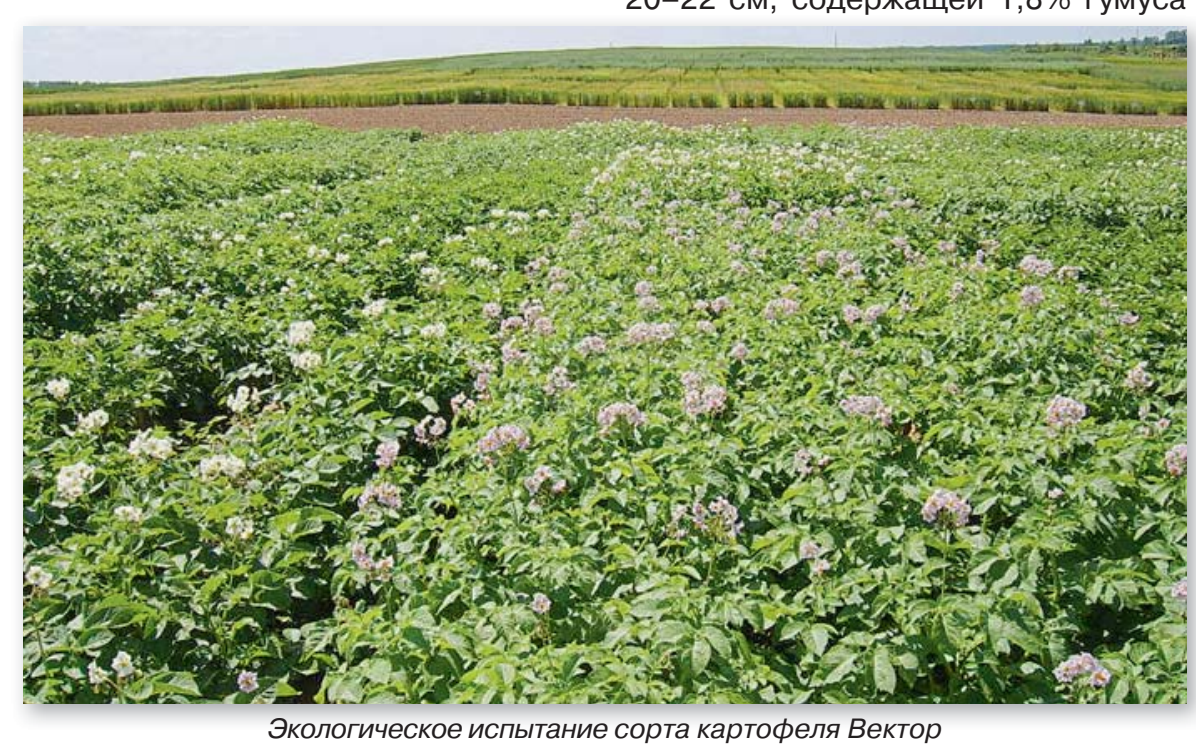

Экологическое испытание сорта картофеля Вектор

В 2016-2018 годах на опытном поле ФГБОУ ВО Смоленская ГСХА изучали отзывчивость среднеспелого сорта картофеля Вектор на способы, сроки посадки и применение регуляторов роста (рис.).

Цель исследований: оценка способов, сроков посадки клубней среднеспелого сорта картофеля Вектор и выявление наименее энергозатратного способа.

Двухфакторный и однофакторный полевые опыты были заложены в шестипольном севообороте кафедры агрономии, землеустройства и экологии на дерново-подзолистой среднесуглинистой почве, имеющей глубину пахотного горизонта 20-22 см, содержащей 1,8\% гумуса

№10/2019 Картофель и овощи (по Тюрину), подвижных форм фосфора (по Кирсанову) - 122 мг/Кг, обменного калия (по Кирсанову) $186 \mathrm{Mг} / \mathrm{Kг,} \mathrm{pH}_{\text {сол. }} 5,8$.

Опыт со сроками и способами посадки включал: фактор A - гребневой способ посадки и без предварительной нарезки гребней; фактор В - сроки посадки: первый - при физической спелости почвы (27-30 апреля), последующие четыре - с интервалом 5-7 дней. Схема посадки $70 \times 30$ см (47,6 тыс. клубней/га). Размещение делянок в опыте рендомизированное, в четырехкратной повторности, площадь опытной делянки - 20 м². $^{2}$.

Эффективность применения бактериальных препаратов (Байкал ЭМ1, Эпин Р Экстра, Альбит) и регулятора роста (Новосил) при выращивании картофеля сорта Вектор изучали в полевом однофакторном опыте. Бактериальными препаратами обрабатывали клубни картофеля в день посадки и опрыскивали вегетирующие растения в фазе бутонизации, а регулятором роста проводили трехкратное опрыскивание растений в фазе начала цветения, полное цветение и через неделю в дозах, рекомендованных изготовителями.

Закладку опытов, учеты, наблюдения, анализы проводили согласно Методике Госсортоиспытания (1985) и соответствующим ГОСТ.

Предшественник - люпин на сидерат. Агротехника в опыте общепринятая для Нечерноземной зоны РФ.

Метеорологические условия 2016-2018 годов были неодинаковыми, что позволило испытать элементы технологий при разной обеспеченности вегетационных периодов осадками и теплом.

Погодные условия наряду с изучаемыми агроприемами влияли на рост и развитие растений картофеля.

В среднем продолжительность вегетационного периода сорта Вектор находилась в пределах 91- 
Таблица 1. Влияние способов и сроков посадки на урожайность и качество клубней картофеля (в среднем за 2016-2018 годы)

\begin{tabular}{|c|c|c|c|c|c|c|c|c|}
\hline Способ посадки (А) & $\begin{array}{c}\text { Срок } \\
\text { посадки } \\
\text { (В) }\end{array}$ & $\begin{array}{c}\text { Полевая } \\
\text { всхожесть,\% }\end{array}$ & $\begin{array}{c}\text { Выжи- } \\
\text { ваемость, \% }\end{array}$ & $\begin{array}{c}\text { Густота } \\
\text { стояния } \\
\text { стеблей, } \\
\text { тыс. шт/га }\end{array}$ & $\begin{array}{c}\text { Площадь } \\
\text { листовой } \\
\text { пове- } \\
\text { рхности, } \\
\text { тыс. } \text { м }^{2} / \text { га }\end{array}$ & $\begin{array}{c}\text { Фото- } \\
\text { синтетический } \\
\text { потенциал } \\
\text { посадок, млн } \\
\text { м².сут./га }\end{array}$ & $\begin{array}{c}\text { Уро- } \\
\text { жайность, } \\
\text { т/га }\end{array}$ & $\begin{array}{l}\text { Содержание } \\
\text { крахмала,\% }\end{array}$ \\
\hline \multirow{5}{*}{$\begin{array}{l}\text { Посадка без предва- } \\
\text { рительной нарезки } \\
\text { гребней }\end{array}$} & 1 & 92 & 96 & 126 & 34 & 1,7 & 26,8 & 17,2 \\
\hline & II & 93 & 96 & 150 & 37 & 1,9 & 31,7 & 16,9 \\
\hline & III & 96 & 98 & 222 & 40 & 2,0 & 36,4 & 16,7 \\
\hline & IV & 97 & 98 & 226 & 36 & 1,6 & 32,2 & 16,7 \\
\hline & v & 96 & 97 & 179 & 32 & 1,4 & 28,2 & 16,8 \\
\hline Среднее & & 95 & 97 & 181 & 36 & 1,7 & 31,1 & 16,9 \\
\hline \multirow{5}{*}{ Гребневая посадка } & 1 & 94 & 96 & 216 & 36 & 1,8 & 32,9 & 17,3 \\
\hline & II & 96 & 98 & 222 & 40 & 2,1 & 39,1 & 17,0 \\
\hline & III & 98 & 98 & 229 & 38 & 2,0 & 37,9 & 17,1 \\
\hline & IV & 96 & 97 & 177 & 34 & 1,5 & 25,4 & 16,8 \\
\hline & v & 96 & 97 & 154 & 30 & 1,2 & 21,2 & 16,7 \\
\hline Среднее & & 96 & 97 & 200 & 36 & 1,7 & 31,3 & 17,0 \\
\hline $\begin{array}{l}\mathrm{HCP}_{05} \text { средние по } \\
\text { опыту }\end{array}$ & - & - & - & - & - & - & 1,4 & - \\
\hline $\begin{array}{l}\text { HCP }_{05} \text { способы } \\
\text { посадки }\end{array}$ & - & - & - & - & - & - & 0,3 & - \\
\hline $\mathrm{HCP}_{05}$ сроки посадки & - & - & - & - & - & - & 1,2 & - \\
\hline
\end{tabular}

92 дней. Способы посадки существенно не повлияли на этот показатель. В зависимости от сроков посадки длина вегетационного периода варьировала в пределах 7 дней. Более ранняя посадка приводила к увеличению этого показателя.

Полевая всхожесть, определяемая отношением числа взошедших растений к количеству высаженных клубней в процентах, в опыте колебалась от 92 до 98\% и имела тенденцию к повышению при гребневой посадке. При обоих способах посадки картофеля данный показатель оказался наибольшим (9798\%) при третьем, четвертом сроках посадки.

Выживаемость растений картофеля оказалась достаточно высокой, колебалась в пределах 96-98\%. Наибольшие ее значения были на третьем-четвертом сроках посадки при посадке без предварительной нарезки гребней и на втором-третьем сроках при гребневом способах посадки.

Продуктивность посадок картофеля во многом определяется густотой стояния стеблей на единице площади. Считается, что для продовольственного картофеля эта величина должна составлять 200-250 тыс. шт/ га [5, 6]. В наших исследованиях этот показатель варьировал в пределах 126-229 тыс. шт/га и в значительной мере определялся приемами агротехники. При гладкой посадке, в среднем, густота стеблестоя со- ставила 181 тыс., в то время как при гребневой - 200 тыс. шт/га. При обоих способах посадки густота стояния стеблей достигала максимальной плотности при третьем сроке ее проведения.

Наибольшая площадь листовой поверхности в посадках картофеля колебалась в пределах 32-40 тыс. м²/ га. Величина показателя не зависела от способов посадки и существенно определялась ее сроками. При посадке без предварительной нарезки гребней наибольших размеров фотосинтезирующая поверхность достигала при третьем сроке посадки, при гребневой - при втором. В этих же вариантах данные по фотосинтетическому потенциалу были наиболее высокими и составили 2,0-2,1 млн м² сут/га.

Урожайность основной продукции - один из главных показателей оценки сорта или агроприема. Данные, полученные в опыте, свидетельствуют о различном влиянии технологических приемов на урожайность картофеля (табл. 1).

В целом, способы посадки картофеля существенно не повлияли на урожайность, в тоже время в зависимости от сроков посадки наблюдалось значительное ее варьирование. В среднем, наибольшая урожайность (37,9 т/га) получена при третьем сроке посадки.

Представляют интерес данные по колебанию сборов продукции в зави- симости от сроков в пределах каждого из способов посадки. При посадке без предварительной нарезки гребней наибольшая урожайность получена при проведении посадки в третий срок; как более ранняя, так и более поздняя посадка вызывали плавное снижение ее значений. При гребневой посадке урожайность достигала максимума при втором сроке; более поздняя посадка вызывала резкое падение ее величины.

Изучаемые агроприемы не оказали существенного влияния на крахмалистость клубней (16,7-17,3\%). Их дегустационная оценка оказалась более высокой при поздних сроках посадки, чем при ранних (4,3-4,4 баллов).

Под действием биопрепаратов и регуляторов роста полевая всхожесть картофеля возросла на 2-5,9\%, что позволило увеличить сохранность клонов и в целом урожайность картофеля. В результате в этом варианте отмечено наибольшее количество растений картофеля на 1 га.

Количество стеблей на один куст картофеля и высоту растений определяли в начале цветения. Наименьшее количество стеблей растения картофеля образовали в 2016 году - 4,9-6,0 шт/раст., а наибольшее в 2018 году - 7,4-7,9 шт/раст., что связано с условиями вегетации. В среднем за три года наблюдений применение регуляторов 
Таблица 2. Влияние регуляторов роста на формирование урожайности и качество клубней картофеля (в среднем за 2016-2018 годы)

\begin{tabular}{|c|c|c|c|c|c|c|c|}
\hline \multirow[b]{2}{*}{ Вариант } & \multirow{2}{*}{$\begin{array}{c}\text { Средняя } \\
\text { урожайность, } \\
\text { т/га }\end{array}$} & \multirow{2}{*}{$\begin{array}{c}\text { Полевая } \\
\text { всхожесть,\% }\end{array}$} & \multirow{2}{*}{$\begin{array}{c}\text { Количество } \\
\text { растений, } \\
\text { шт./га }\end{array}$} & \multirow{2}{*}{$\begin{array}{l}\text { Количество } \\
\text { стеблей, } \\
\text { шт/раст. }\end{array}$} & \multicolumn{3}{|c|}{ Показатели качества } \\
\hline & & & & & $\begin{array}{c}\text { сухое } \\
\text { вещество,\% }\end{array}$ & крахмал,\% & $\begin{array}{c}\text { витамин C, } \\
\text { мг\% }\end{array}$ \\
\hline $\mathrm{N}_{80} \mathrm{P}_{120} \mathrm{~K}_{140}-$ ФОН & 32,5 & 94,1 & 44864 & 5,4 & 24,6 & 18,2 & 10,8 \\
\hline Фон + Байкал ЭМ-1 & 36,4 & 100 & 47612 & 5,8 & 24,7 & 19,2 & 11,9 \\
\hline Фон+Эпин & 35,6 & 96,1 & 45838 & 6,1 & 25,1 & 18,1 & 10,1 \\
\hline Фон+Альбит & 37,4 & 98,0 & 46697 & 6,2 & 24,8 & 18,6 & 12,2 \\
\hline Фон+Новосил & 38,8 & 98,1 & 46753 & 6,2 & 25,8 & 18,5 & 11,6 \\
\hline
\end{tabular}

роста способствовало увеличению числа стеблей на 6-13\%.

Продуктивность посадок картофеля во многом определялась густотой стояния стеблей на единице площади. Количество стеблей, сформировавшихся на 1 га, в наших исследованиях колебалось от 205 до 266 тыс. шт/га и наибольшим было при применении препаратов Альбит и Новосил. В этих вариантах растения картофеля оказались выше, чем на фоновом варианте на 1,4-2,0 см.

В зависимости от погодных условий в период вегетации урожайность картофеля колебалась от 18,0 до 49,8 т/га. Наибольшей она была в 2016 году и составила 18,0-26,4 т/га, а в 2018 году - 42,0-49,8 т/га. Применение при выращивании картофеля биопрепаратов и химических регуляторов роста привело к получению достоверной прибавки урожая во все годы исследований. В среднем за три года исследований урожайность культуры от применяемых препаратов возросла на 14\% и наибольшей оказалась при использовании препаратов Новосил и Альбит - 38,8 и 37,4 т/га соответственно (табл. 2).

Определение структуры урожая показало, что применение регуляторов роста увеличило число и массу клубней с куста.

Обработка стимуляторами роста повысила не только урожайность, но и качество клубней. Так, содержание крахмала в клубнях картофеля на 0,3-1\%, аскорбиновой кислоты на 7,4-13\%.

Полученные данные обосновывают высокую эффективность применения биологических препаратов Байкал ЭМ-1, Альбит и регулятора роста Новосил. Они способствовали повышению урожайности картофеля и улучшению качества продукции. Из изученных препаратов наиболее эффективными оказались Новосил и Альбит.

Без энергетической оценки нет полного анализа эффективности изучаемых агроприемов. Полученные данные показывают, что затраты энергии на возделывание картофеля в зависимости от способов посадки в оптимальные сроки посадки составляли 87-88 ГДж/га

Чистый энергетический доход при возделывании картофеля сорта Вектор составил 37-43 ГДж/га, причем более эффективное его выращивание оказалось при гребневом способе посадке.

С энергетической точки зрения, любой агротехнологический прием считается эффективным, если коэффициент энергетической эффективности, определяемый отношением полученной с урожаем энергии к затратам совокупной энергии на единицу площади, равен или, что лучше, превышает 1.

Этот показатель при гладком способе посадки картофеля составил 1,4; при гребневом - 1,5.

При посадке без предварительной нарезки гребней энергетическая себестоимость продукции составляла 3,3 ГДж/т; при гребневом - данный показатель несколько снижался.

Таким образом, проведенными исследованиями установлено, что среднеспелый сорт картофеля Вектор на дерново-подзолистой среднесуглинистой среднеокультуренной почве при посадке в предварительно нарезанные гребни, а также с применением ростовых препаратов Новосил и Альбит способен формировать урожайность клубней 38-39 т/га.

\section{Библиографический список}

1.Постников А.Н., Постников А.А. Картофель. М.: MCXA, 2002. 75

2.Коршунов А.В., Семенов А.В. Приемы агротехники влияют на урожай и его качество // Картофель и овощи. 2003. № 3. С. 8-9.

3.Романова И.Н., Карамулина И.А. Оптимальные сроки посадки // Картофель и овощи. 2007. № 3. С. 7.

4.Усанова 3.И., Васильев А.С. Формирование продуктивности разных сортов картофеля под влиянием некорневых подкормок высокотехнологичными препаратами // Земледелие. 2016. № 5. С. 33-36.

5.Романова И.Н., Князева С.М., Птицына Н.В., Терентьев С.Е., Карамулина И.А. Продуктивность сортов картофеля разных экотипов в зависимости от условий выращивания // Научно-практический журнал «Природообустройство». 2018. №5. С. 103-108.

6.Ториков В.Е., Котиков М.В., Богомаз М.А. и др
Сорта картофеля интенсивного типа. Брянск: Изд-во Брянского ГАУ, 2017. 76 с.

\section{Об авторах}

Романова Ираида Николаевна, доктор с. - х. наук, профессор кафедры агрономии, землеустройства и экологии.

E-mail: iraidarom@yandex.ru Терентьев Сергей Евгеньевич, канд. с. - х. наук, доцент кафедры технологии переработки с. - х. продукции. E-mail: sgsha.nauka@mail.ru Перепичай Марина Игоревна, канд. с. - х. наук, ст. преподаватель кафедры агрономии, землеустройства и экологии

E-mail: bibikova.m@yandex.ru

Мартынова Ксения Викторовна, аспирант кафедры агрономии, землеустройства и экологии.

E-mail: hariton_93@mail.ru ФГБОУ ВО Смоленская ГСХА

Time, methods of planting and growth regulators as elements of resourcesaving technology of potato growing

I.N. Romanova, $D S c$, professor of the department of agronomy, land management and ecology. E-mail: iraidarom@yandex.ru

S.E. Terentyev, PhD, associate professor of the department of technology of processing of agricultural products.

E-mail: sgsha.nauka@mail.ru

M.I. Perepechai, $P h D$, senior lecturer of the Department of agronomy, land

management and ecology.

E-mail: bibikova.m@yandex.ru

K.V. Martynova, postgraduate student of the Department of agronomy, land

management and ecology.

E-mail: hariton93@mail.ru

Smolensk State Agricultural Academy

Summary. The research was carried out to study the methods, time of tubers planting of medium-ripening potato varieties, and to identify the least energy-consuming method. Studies have shown that in conditions of Non-chernozem zone potato variety allows the Vector to yield 36-38 t/ha was the least energy-intensive raised bed method of planting.

Keywords: potatoes, planting time, planting methods, resource-saving technologies, yield, growth regulators. 